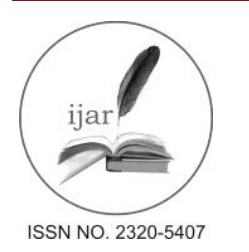

Journal homepage: http://www.journalijar.com
Journal DOI: 10.21474/IJAR01

INTERNATIONAL JOURNAL

OF ADVANCED RESEARCH

RESEARCH ARTICLE

\title{
ROLE OF TEACHERS IN ENHANCING VISUAL EFFICIENCY OF CHILDREN WITH LOW VISION THROUGH FUNCTIONAL VISION TRAINING.
}

\author{
Dhanalaksmi .K. \\ Research Scholar, Ramakrishna Mission Vivekananda University, Faculty of Disability Management and Special \\ Education, Coimbatore-641 020, Tamil Nadu.
}

\section{Manuscript Info}

Manuscript History:

Received: 14 April 2016

Final Accepted: 19 May 2016

Published Online: June 2016

Key words:

Vision Training, Children with Low

Vision, Visual Efficiency.

*Corresponding Author

Dhanalaksmi .K.

\begin{abstract}
The development of visual ability is not natural. It requires stimulation and motivation to use remaining vision in a variety of environments. A low vision child, owing to uncertain and frustratingly limited vision, may not always be motivated to use vision to control and manipulate the environment to achieve the specific goals. The main aim of vision training is to encourage and help each low vision child make use of his best residual vision and to provide a variety and number of opportunities for the child to learn about and understand his environment(Jill Keeffe, 1992). Low Vision as a level of vision that with standard correction hinders an individual in the planning and/or execution of a task, but which permits enhancement of the functional vision through the use of optical or non-optical devices, environmental modifications and/or techniques (Anne Corn, 1989).Designated children with low vision as those who have limitations in distance, but are able to see objects and materials within a few inches or at a maximum of a few feet away (Natalie Barraga, 1983). Visual efficiency refers to the extent which available vision is used effectively. Effective use of residual vision leads to efficient performance in the area of education, employment and environment. The present paper gives the overview of vision training procedure to improve the visual efficiency of children with low vision.
\end{abstract}

\section{Introduction:-}

Vision is a cognitive act which enables us to look at an object and not only identify it but to determine where it is, its size its distance from the observer, its rate of movement its texture and everything else that can be determined by visual inspection. Eye sight which involves the sensory ability of the eye to distinguish small details is only one component of vision.

\section{The Visual System:-}

The visual system is made up of three basic parts: the eyes, the optic nerve, and the brain. Specific visual elements that assist in building a visual image include central visual acuity, peripheral (side) vision, binocular vision (which aids with depth perception), night vision, color vision and contrast sensitivity. The eye works very much like a camera, with light coming into the eye through the cornea and traveling through the lens of the eye with the iris functioning as an aperture to moderate the amount of light allowed to enter the eye. The light waves are bent by both the cornea and the lens so that they converge at a specific point on the retina, called the macula. If they do not converge exactly in the right place, the person may need glasses or contact lenses to assist them in seeing clearer. The retina is the tissue which holds the photoreceptor cells (like the film of a camera) and covers the inside of the rear chamber of the eye. The photoreceptor cells (rods and cones) and their attached network in the retinal pigment epithelium are where the light rays are changed into neural-electric impulses that travel along the optic nerve to the 
occipital lobe of the brain. What an individual actual sees is composed of image, color, and movement, and is put together in the brain. Damage anywhere along the optic pathway from the cornea of the eye to the brain can cause vision impairment (Blindness and Low vision).

No matter the cause of vision loss, how an individual uses their remaining vision can vary tremendously from person to person or in different environments. Additional personal and environmental factors affecting the interpretation of vision include factors such as fatigue, personality, experience, novelty, complexity, lighting, contrast, and glare. These factors can enhance or complicate the individual's interpretation of what is seen (Corn 1983). For children with vision loss, learning to interpret their environment is one of the challenges of having low vision and often requires specialized instruction.

The effects of low vision are not the same for all people. Differences occur in the amount of vision for distant and near objects, visual field, ability to see the objects which have poor contrast, colour vision and the effect of lights on vision.

Need for functional vision training and improvement of visual efficiency; Related reviews:-

Barraga (1964) investigates that vision discrimination activity improves visual efficiency of student with Low Vision. Studies suggest that enhances distance vision through more complex visual skills and depth cues (Smith .A.\& O’Donnell- 1994). Barraga N.C \& Morris J. E (1980) studies that to develop Visual Efficiency through diagnostic assessment kit. Develop and demonstrate a curriculum in Vision Stimulation and training in the use of Low Vision Aids to improve the Visual Functions of Visually Impaired students (Cook .K. M, Lussier A.J \& Arthur J.F.-1992). Farrell.L.(1996) suggests that collect information from the students regards getting the diagnosis(Functional Vision Assessment checklist) understanding the diagnosis, diagnostically related intervention and case reports. Erhardt R.P (1990), presents and compares for basic models for the management and remediation of visual problem in children with multiple impairments. Corn A. L \& Koening A. J. (1996) says that, real life sense of what Low Vision is, what the need of people with Low Vision are and what to effective delivery of low vision service entails. Smith \& Cote (1982) concentrates on background infection as well as evaluation and teaching strategies necessary for educators who wish to help multiply impaired children reach their optimum levels of visual functions. Levack .N. (1991) suggests guidelines for assessing a student's visual functioning and implementing programme that will enhance student's visual functioning. Rebecca Marinoff (2012) reported that vision therapy techniques used to train ocular skills, strabismus and ambliyopia can be modified to enhance efficient eccentric viewing posture in patients with central scotoma. Knowlton M. (1997) investigates on efficiency in visual scanning, by children with and without visual disabilities. This study gave the positive result on children with and without visual disabilities. Nutheti .R. (2004) examined about perceived visual ability for function vision performance among person with Low Vision in the Indian State of Andhra Pradesh. This study shows that determination of the disabilities of perceived visual ability for functional vision performance among persons with low vision in the Indian state of Andhra Pradesh.

\section{Functional vision assessment:-}

Functional vision is the ability of a person to use his remaining vision effectively. Functional vision skills can help the person in everyday activities.

\section{Importance of functional vision training:-}

1. It helps to determine the current visual functioning level of the person.

2. It helps to determine the extent of visual stimulation and instruction needed to help the person make optimum use of the remaining vision.

3. It enables the person to use his limited vision to the highest potential.

4. It helps to plan the person's mobility training programme.

5. It helps in decisions regarding the use of visual stimulation materials.

6. It helps to decide upon the nature of the primary reading medium.

7. It enables one to decide on the type of devices needed by the person.

Guidelines for vision training:-

1. Selecting objects for vision training

- Choose familiar and interesting objects.

- Use objects of daily use(food items and play things). 
- Use appropriate size, distance, contrast, colour, position, light in and around the object etc.

2. Information to be recorded while giving vision training.

- The objects used for the vision training.

- How easy or difficult it was for the person to give the vision training?

- The person's comments about the task.

- Behaviour of the person during the vision training.

- Distance of the test items.

- Time taken to complete each activity.

Functional vision Training:-

Visual efficiency can be developed through following activities.

Visual awareness: It refers to the ability of the child to identify the objects present in the visual field.

This is the basic skill that has to be developed in a person who has low vision.

Ex: Moving familiar object in front of the eyes of the child.

Visual attention: It refers to the ability of the child to attend the objects in front of the child.

Ex: Drawing the child's attention using a rattle ball.

Visual fixation: The ability of the child to fix the eyes on the moving object.

Ex: Moving an object in front of the eyes and asking the child to fix its sight on it.

Visual focus: The ability of the child to see a known object at various distances.

Ex: Keeping known objects from $1 \mathrm{~m}$ to $6 \mathrm{~m}$ and asking to name them.

Visual fusion: The ability of the child to see the object as one.

Ex: Asking the child to use his eyes to see only rolling ball on the floor.

Visual tracking: This refers to the child's ability to follow a moving object with his eyes.

Ex: Asking the child to catch the bubbles of soap water.

Visual scanning: This refers to the child's ability to search for a particular stimulus among other visual stimuli.

Ex: Asking the child to pick an iron nail using a magnet.

Visual discrimination: This refers to the child's ability to distinguish different objects on the basis of their colour, shape or size.

Ex: Ask the child to differentiate the shapes.

Visual figure ground discrimination: This refers to the child's ability to isolate a particular object or a picture from the background.

Ex: The child is given a picture and asked to circle a flower in the picture.

Visual memory: This refers to the child's ability to store and recall past experiences and integrates them with new ones.

Ex: The child is asked to identify a well known person form the photograph.

Visual Closure: This refers to the child's ability to perceive a total picture or objet when a part is visible/available. Ex: Show a picture of any object with a part missing.

Visual spatial relations: This refers to the child's ability to identify spatial concepts like directions, distance etc.

Ex: Asking the child to show the directions.

Visual mobility: This refers to the child's ability to identify right and left concepts through movement.

Ex: Asking the child to move to left hand side or to right hand side. 
Eye hand coordination: This ability to perform a task using our hands and eyes in coordination is referred as eyehand coordination.

Ex: Asking the child to colour the picture without going out of the boundaries.

Eye foot coordination: This refers to the child's ability to perform a task using eyes and foot in harmony.

Ex: Asking the child to step on the circle markings drawn on the floor.

Form constancy: This refers to the child's ability to perceive the same object at different positions.

Ex: Ask the child to identify a picture showing an object in different positions.

\section{Conclusion:-}

Visual efficiency is most important aspect in children with Low Vision. Functional vision training enhances the visual efficiency of student with Low Vision through visual awareness, attention, fixation, focus, fusion, tracking, scanning, memory, closure etc. For making children with Low Vision more independent in education, access environment and employment functional vision training plays crucial role. So, Teacher should understand the procedures to improve the visual efficiency of children with low vision.

\section{References:-}

1. Barraga, N. C. (1964). Increased visual behavior in low vision children. New York: American Foundation for the Blind.

2. Barraga, N. C., \& Morris, J. E. (1980). Program to develop efficiency in visual functioning: Diagnostic Assessment Procedure. Louisville, KY: American Printing House for the Blind.

3. Cook, K.M., Lussier, A.J., \& Arthur, J.F. (1992). Volume V-E: Project IVEY: Increasing visual efficiency. A resource manual for the development and evaluation of special programs for exceptional students. Tallahassee, FL: State of Florida Department of Education.

4. Corn, A., \& Koenig, A. (1996). Perspectives on low vision. In A. Corn \& A. Koenig (Eds.), Foundations of low vision: Clinical and functional perspectives . New York: American Foundation for the Blind.

5. Erhardt, R. (1990). Developmental visual dysfunction . Tucson, AZ: Therapy Skill Builders. Exceptional children. SAGE.

6. Ferrell, K.A. (1996). Reach out and teach: Meeting the training needs of parents of visually and multiply handicapped young children. Parent handbook. New York: American Foundation for the Blind Press.

7. Knowlton M (1997). Efficiency in visual scanning by children with and without visual disabilities.

8. Levack, N. (1991). Low vision: A resource guide with adaptations for students with visual impairments . Austin, TX: Texas School for the Blind and Visually Impaired.

9. Nutheti R (2004).Perceived visual ability for functional vision performance among persons with low vision in the Indian state of Andhra Pradesh. Investigate ophthalmology and visual science. PubMed Journals.

10. O'Donnell, L. M., \& Smith, A. J. (1994). Visual cues for enhancing depth perception. Journal of Visual Impairment and Blindness, 88(3), 258- 266.

11. Rebecca Marinoff (2012). Using Vision Therapy to Maximize Visual Efficiency for Low Vision Patients with Central Scotoma. State University of New York College of Optometry, New York.

12. Smith, A., \& Cote, K. (1982). Look at me. A resource manual for the development of residual vision in multiply impaired children. Philadelphia: Pennsylvania College of Optometry Press. 